\title{
Extended Endoscopic Endonasal Approach for a Giant Parasellar Epidermoid Cyst
}

\author{
Sorin Aldea ${ }^{1}$ Mathieu Veyrat ${ }^{2} \quad$ Pierre Bourdillon $^{1} \quad$ Denis Ayache $^{2} \quad$ Caroline Le Guérinel $^{1}$ \\ ${ }^{1}$ Department of Neurosurgery, Rothschild Foundation Hospital, Paris, \\ France \\ 2 Department of Otolaryngology-Head and Neck Surgery, Rothschild \\ Address for correspondence Sorin Aldea, MD, Department of \\ Neurosurgery, Rothschild Foundation Hospital, 25 rue Manin, 75019 \\ Paris, France (e-mail: saldea@for.paris).
}

Foundation Hospital, Paris, France

J Neurol Surg B Skull Base 2022;83(suppl S3):e653-e654.

\begin{abstract}
Keywords

- endoscopy

- parasellar area

- epidermoid cyst

Epidermoid cysts are rare lesions which typically grow slowly. For this reason, these lesions are usually discovered when they are already very large. The parasellar location is no exception to this rule and may involve the cavernous sinus or the Meckel cave. We present a 34-year-old female patient without past medical history who was admitted in our tertiary referral center for episodes of diplopia in the right lateral gaze and right trigeminal dysesthesias. Brain magnetic resonance imaging (MRI) showed a large right parasellar mass with mixed intensity signal on the $\mathrm{T} 1$ and $\mathrm{T} 2$ sequences, without contrast enhancement and a typical hypersignal intensity on diffusion-weighted sequences evoking an epidermoid cyst. We discuss the radiologic criteria which differentiate the lesions originating in the cavernous sinus from those of the Meckel cave (-Figs. 1 and $\mathbf{2}$ ).

Parasellar tumors may be approached through classical transcranial approaches such the epidural temporopolar or the subtemporal approach which involve a significant degree of brain retraction. The last decade witnessed the advent of extended endonasal approaches which offer an interesting alternative and avoid the manipulation of the brain. We used the endoscopic transpterygoid approach in our patient and we were able to achieve an excellent clinical and radiological result. We discuss the nuances of the technique and present the surgical steps of the procedure (-Figs. 3 and $\mathbf{4}$ ).

The endoscopic endonasal approach represents an excellent therapeutic option for parasellar lesions. A thorough knowledge of the anatomy and experience with endoscopic techniques are obvious prerequisite.

The link to the video can be found at: https://youtu.be/QonSvHrCwOU.
\end{abstract}

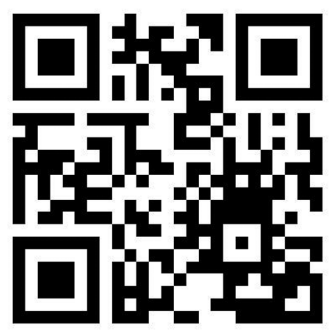

received

March 29, 2020 accepted after revision January 10, 2021 published online May 3, 2021

www.thieme.com/skullbasevideos

www.thieme.com/jnlsbvideos

DOI https://doi.org/ 10.1055/s-0041-1727127. ISSN 2193-6331.

\footnotetext{
(C) 2021. The Author(s).

This is an open access article published by Thieme under the terms of the Creative Commons Attribution-NonDerivative-NonCommercial-License, permitting copying and reproduction so long as the original work is given appropriate credit. Contents may not be used for commercial purposes, or adapted, remixed, transformed or built upon. (https://creativecommons.org/ licenses/by-nc-nd/4.0/) Georg Thieme Verlag KG, Rüdigerstraße 14, 70469 Stuttgart, Germany
} 


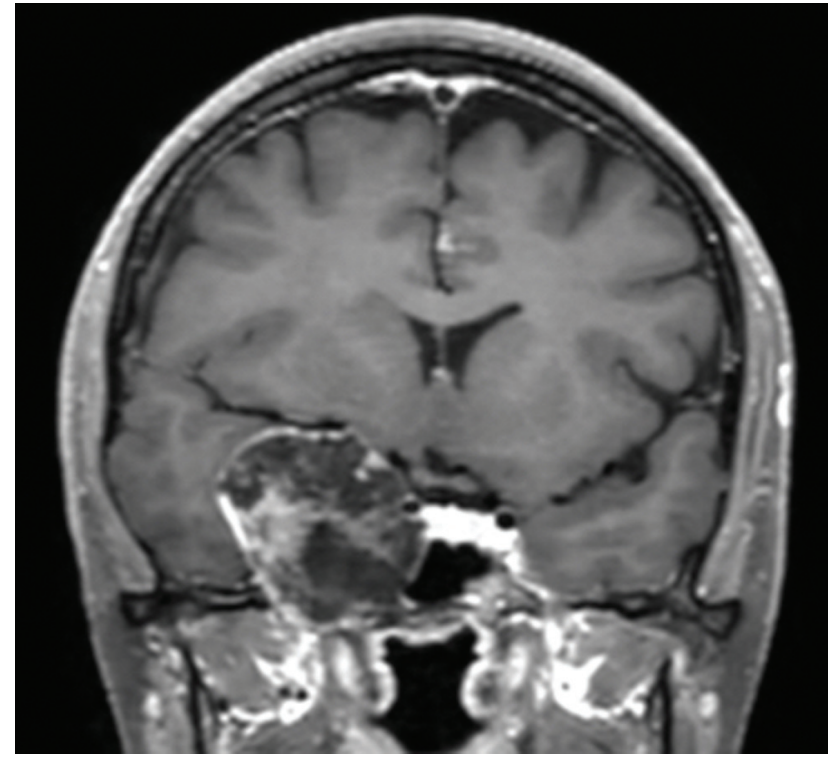

Fig. 1 Preoperative contrast-enhanced T1 MRI showing a large parasellar epidermoid cyst. MRI, magnetic resonance imaging.

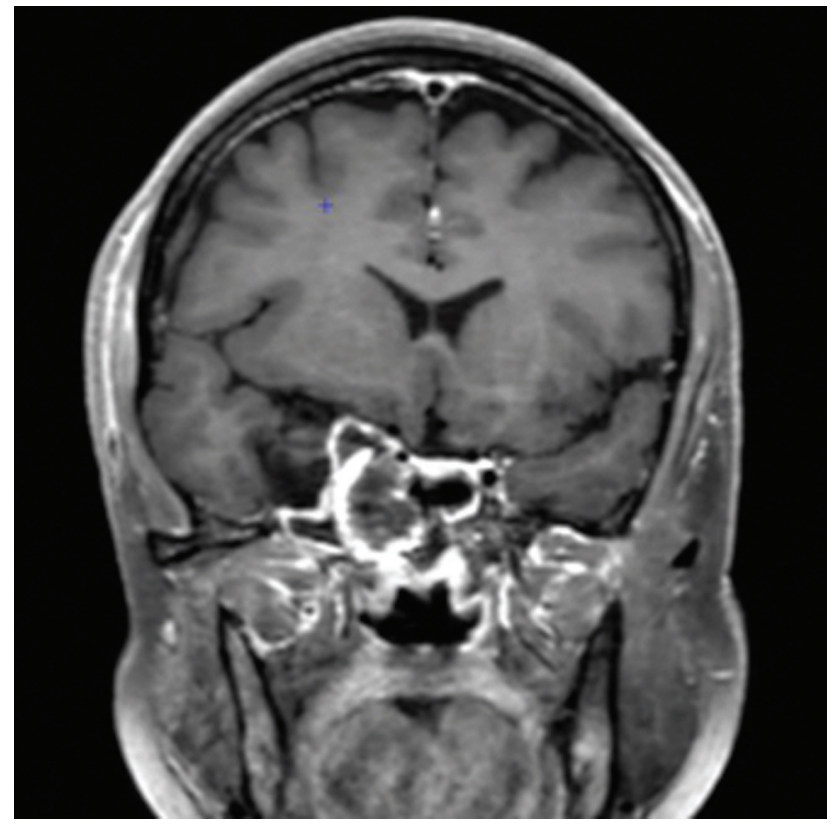

Fig. 3 Postoperative contrast-enhanced T1 MRI showing subtotal resection of the epidermoid cyst. MRI, magnetic resonance imaging.

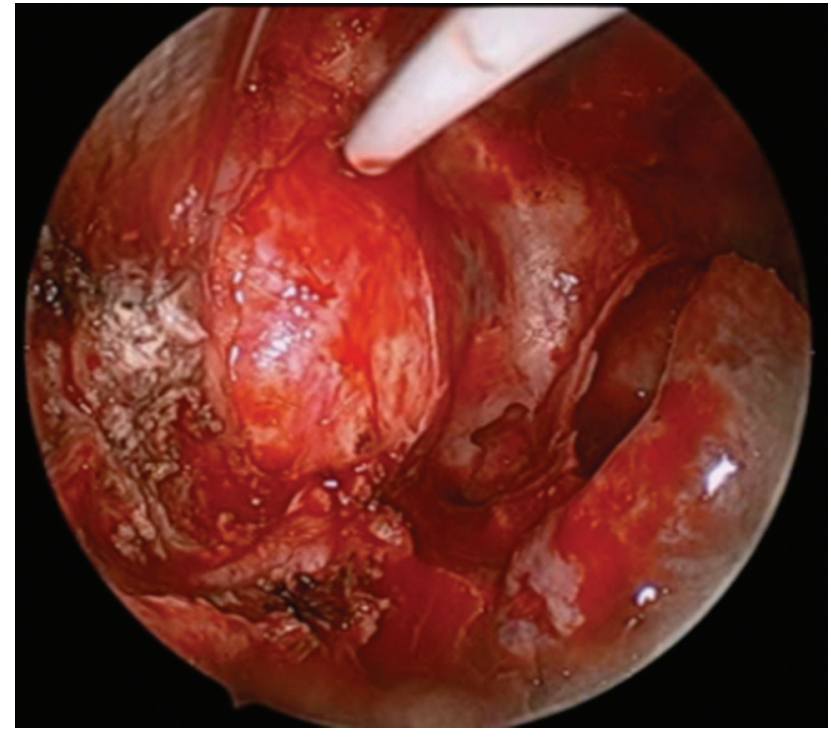

Fig. 2 Initial exposure of the tumor bulging in the sphenoid sinus.

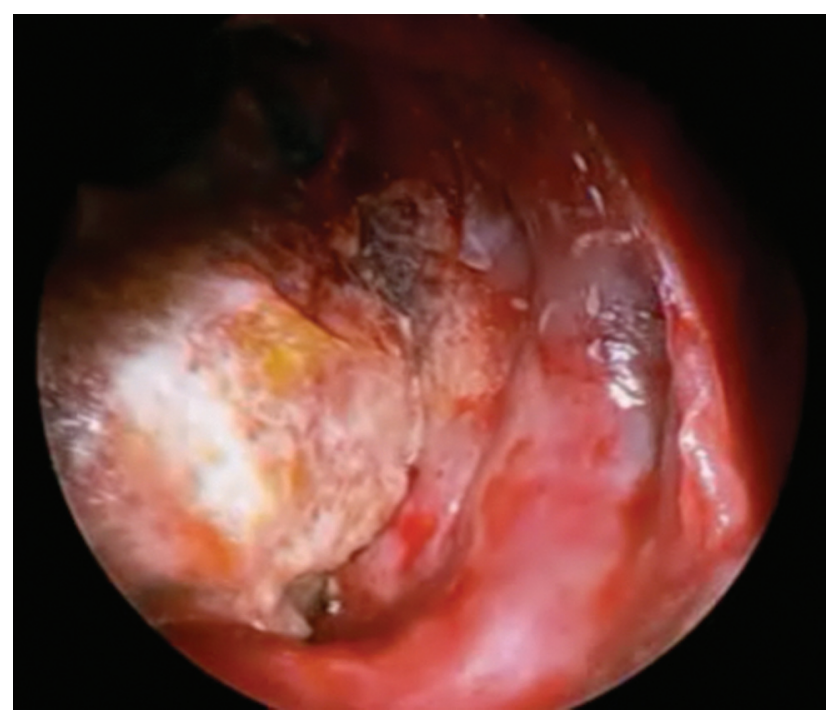

Fig. 4 The operative cavity at the end of the resection showing the junction of the right petrous and paraclival internal carotid artery.

Conflict of Interest

None declared. 